\title{
Fatigue Resistance Study of Quenched and Tempered High-Strength Steel Submitted to Low Intensity Shot Peening Treatments with Different Types of Shots
}

Segurado $E^{*}$, Belzunce FJ and Fernández Pariente I

Polytechnic School of Engineering of Gijón, University Campus, University of Oviedo, 33203 Gijón, Spain

\begin{abstract}
The aim of this research is to study the fatigue life enhancement produced in quenched and tempered AISI4340 steel with a tensile strength of $2000 \mathrm{MPa}$ after being submitted to shot peening surface treatments. These treatments generate compressive residual stress fields in a superficial layer of the material at the same time as inducing some kind of damage on the surface. Different kind of projectiles were chosen to perform the treatment (ceramic and steel shots), studying the way these affected the fatigue life of the specimens.

The surface topography of the samples was analysed using a roughness tester and by means of scanning electron microscopy (SEM). The compressive residual stress profile induced by these treatments was measured using X-ray diffraction (XRD) plus electro-polishing. The fatigue behaviour of the treated samples was subsequently studied by means of 4-point rotating bending tests and their fracture surfaces were analysed using SEM.

The best fatigue performance was obtained after shot peening with ceramic beads under 8AAlmen intensity. The main difference in relation to the treatment performed under the same intensity but using steel cut wire shots was the much lower surface damage induced by the impacts with the ceramic shots compared with the cut wire projectiles, which in turn is justified by the greater geometric perfection and hardness of the former. Furthermore, fatigue specimens shot peened with ceramic beads under $8 \mathrm{~A}$ intensity always gave rise to internal fatigue crack initiation, which took place outside the zone subjected to residual compressive stresses. Moreover, fatigue initiation was always linked to the presence of hard and rigid alumina inclusions, which acted as microstructural stress concentrators.
\end{abstract}

Keywords: Fatigue; Shot peening; Surface treatments; Residual stress; Structural steels

\section{Introduction}

Shot peening is a widely used surface treatment in the aerospace and automotive industries to improve the fatigue life of metal components. When these components are submitted to bending or torsion loads and also when there are stress concentrators, the largest stress occurs in the surface and it is precisely here where fatigue cracks initiate under cyclic loads and then grow until failure of the component.

Shot peening is a mechanical surface treatment specially designed to improve the fatigue behaviour of engineering components. Shot peening consists in blasting tiny spherical beads or balls at high speed onto the metal surface of the component to induce a surface plastic deformation that produces a compressive residual stress profile with a sufficient depth to delay or even avoid the growth of surface cracks under fatigue loads. Shot peening also modifies the surface finish. Furthermore, if the intensity of the treatment is excessive, it can produce superficial defects that may facilitate the easy initiation of surface cracks and thereby impair the fatigue life of the product [1-3].

The optimal peening intensity to obtain the best fatigue performance, which depends on the hardness or the mechanical strength of the treated steel, has been studied by numerous researchers. For instance, Tekeli [4] applied peening intensities between 10A and $30 \mathrm{~A}$ to quenched and tempered SA9245 steel, obtaining the highest fatigue strength when using a $20-25 \mathrm{~A}$ peening treatment while also observing a clear decrease in the fatigue strength for the highest peening intensities. Likewise, Aggarwal et al. [5] studied the effects of shot peening treatments on the fatigue life of tempered martensitic steel with a tensile strength of $1256 \mathrm{MPa}$, obtaining the best fatigue performance with an intermediate Almen intensity of 17A. However, quite different shot peening intensities aimed at increasing the fatigue life of structural steels have been reported by other researchers. For example, an optimum shot peening treatment at quite a low intensity, $6 \mathrm{~A}$, was obtained by Torres and Voorwald [6] on a quenched and tempered 4340 steel grade with a tensile strength of $1864 \mathrm{MPa}$, while Vielma et al. [7] studied this same steel, though tempered at $590^{\circ} \mathrm{C}$ (with a tensile strength of $1197 \mathrm{MPa}$ ), finding that a 10A peening was the surface treatment which maximized the fatigue strength of this specific steel grade. Along this same line of research, Menéndez et al. [8,9] studied different grades of an AISI4340 steel obtained after quenching and tempering at different temperatures, with ultimate tensile strengths of between 764 to $2057 \mathrm{MPa}$, reporting optimal Almen intensity ranges of between $10 \mathrm{~A}$ and $14 \mathrm{~A}$, with a maximum of around $16 \mathrm{~A}$ for steel grades with intermediate tensile strengths. These authors also showed that, under optimal shot peening treatments, fatigue cracks initiated below the surface at a depth where the compressive residual stresses induced in the shot peening treatment disappeared. Hence, under these optimized treatments, the compressive layer is able to fully protect the surface region and crack initiation is displaced to

*Corresponding author: Segurado E, Polytechnic School of Engineering of Gijón University Campus, University of Oviedo, 33203 Gijón, Spain, Tel: +34 9851030 00; E-mail: seguradomaria@uniovi.es

Received October 10, 2017; Accepted November 27, 2017; Published December 07, 2017

Citation: Segurado E, Belzunce FJ, Fernández Pariente I (2017) Fatigue Resistance Study of Quenched and Tempered High-Strength Steel Submitted to Low Intensity Shot Peening Treatments with Different Types of Shots. J Material Sci Eng 6: 401. doi: 10.4172/2169-0022.1000401

Copyright: @ 2017 Segurado E, et al. This is an open-access article distributed under the terms of the Creative Commons Attribution License, which permits unrestricted use, distribution, and reproduction in any medium, provided the original author and source are credited. 
Citation: Segurado E, Belzunce FJ, Fernández Pariente I (2017) Fatigue Resistance Study of Quenched and Tempered High-Strength Steel Submitted to Low Intensity Shot Peening Treatments with Different Types of Shots. J Material Sci Eng 6: 401. doi: 10.4172/2169-0022.1000401

Page 2 of 7

deeper sites, related to the presence of microstructural heterogeneities or stress concentrators, such as hard and rigid non-metallic inclusions.

For the mechanical surface treatment of high strength steels, such as AISI 4340 quenched and tempered at low temperatures, single peening using fine ceramic shots under low Almen intensities are recognized and used industrially to obtain significant high fatigue life improvements under quite low operating peening costs. Peng et al. [10] studied the effects of using alumina ceramic beads with a diameter of $0.3 \mathrm{~mm}$ and a hardness of $700 \mathrm{HV}$ under an Almen intensity of $6 \mathrm{~A}$ compared to using cast steel balls with a diameter of $0.6 \mathrm{~mm}$ and a hardness of $610 \mathrm{HV}$ under an Almen intensity of 20A. Higher compressive stresses and hardness in the first $25 \mu \mathrm{m}$ were measured in the samples peened with ceramic beads, though a lower compressive residual stress depth. In this respect, zirconia is a very interesting ceramic medium, characterized by quite a high specific gravity $(4.6 \mathrm{~g} /$ $\left.\mathrm{cm}^{3}\right)$, high hardness $(1000 \mathrm{HV})$ and excellent toughness. The possibility of obtaining residual stress profiles as deep as those obtained with steel shots using lower Almen intensities has also been reported, while shot consumption can be reduced for the same Almen intensity as zirconia beads are much stronger than other ceramic shots [11].

In this paper, the effectiveness of fine zirconia ceramic beads for shot peening high strength steels was verified and compared with the use of steel shots with the ultimate goal of increasing the fatigue performance of the steel. In this respect, it should be noted that there are scarcely any scientific references in the literature comparing the effect of using zirconia ceramic beads with steel shots on this particular application.

\section{Experimental Procedure}

\section{Materials}

The study was performed on a $41 \mathrm{NiCrMo7-3-2}$ steel (AISI 4340) supplied in bars with a nominal diameter of $16 \mathrm{~mm}$. Table 1 shows the chemical composition of the steel.

The bars were austenitized at $850^{\circ} \mathrm{C}$ for 45 minutes, quenched in water and tempered at $200^{\circ} \mathrm{C}$ for 2.5 hours. The heat treated steel had a final hardness of $552 \mathrm{HV}$. The aforementioned heat treatment was carried out on several steel bars measuring $300 \mathrm{~mm}$ in length. Subsequently, two different types of specimens were machined: (a) flat slices with a thickness of $10 \mathrm{~mm}$, obtained cross-sectioning the bar, and (b) fatigue specimens.
Table 2 shows the values of the elastic modulus (E), yield strength $\left(\sigma_{\mathrm{y}}\right)$, ultimate tensile strength $\left(\sigma_{\mathrm{u}}\right)$, tensile elongation (e), reduction of area (RA) and the constants $\mathrm{k}$ and $\mathrm{n}$ of the Hollomon hardening law $\left(\sigma=\mathrm{K} \varepsilon^{\mathrm{n}}\right)$, obtained in previous studies $[8,9]$.

\section{Shot peening treatments}

Shot peening treatments were performed using a direct compressed air machine (Guyson Euroblast $4 \mathrm{PF}$ ) with a $5 \mathrm{~mm}$ diameter nozzle, a distance between the nozzle and the workpiece of $230 \mathrm{~mm}$ and an impact angle of $90^{\circ}$, in accordance with the SAE J442 [12] and J443 [13] specifications.

These treatments were performed using two different types of shots: cut steel wire with rounded off edges $(\mathrm{CW})$ with diameters of $0.3 \mathrm{~mm}$, 0.5 and 0.7 and zirconia beads, Zirshot Y300 (ZS), with a diameter of 0.3 $\mathrm{mm}$. Table 3 shows the most relevant shots characteristics and peening conditions. An Almen intensity of 8A was used in the comparison of both shots, though higher intensities were also applied with the steel shots. Coverages of $100 \%$ were applied and an additional coverage of $200 \%$ was also employed when using the ceramic shots.

Figure 1 shows SEM images of all the shots, steel cut wire (different sizes) and zirconia beads, while Figure 2 compares the $0.3 \mathrm{~mm}$ steel and ceramic projectiles at a higher magnification. The plastically deformed surface of the steel shots and the perfect spherical shape of the zirconia beads are worth noting.

\section{Roughness measurements}

The roughness measurements were performed using a Mahr Marsurf M300 roughness tester. Roughness was measured in all the specimens after the different treatments. Five roughness profiles were plotted for each specimen and the mean value of the average roughness, $\mathrm{Ra}$, and the maximum roughness, $\mathrm{R}_{\max }$, parameters were obtained. $\mathrm{R}_{\max }$ is the maximum of the five $\mathrm{R}_{\text {imax }}$ within the assessment length of 4.8 $\mathrm{mm}$, where $\mathrm{R}_{\text {imax }}$ is the maximum peak-to-valley height of the profile in each of the five aforementioned measurements.

\section{Determination of the compressive residual stress profile}

Residual stress was determined by means of the X-ray diffraction technique using the $\sin 2 \psi$ method on the flat specimens, while the FWHM parameter (diffraction peak width at half maximum height) was simultaneously measured as a parameter related with the induced hardening $[14,15]$. In order to define the residual stress profiles, thin

\begin{tabular}{|c|c|c|c|c|c|}
\hline $\mathrm{C}$ & $\mathrm{Mn}$ & $\mathrm{Si}$ & $\mathrm{Ni}$ & $\mathrm{Cr}$ & $\mathrm{Cu}$ \\
\hline 0.41 & 0.71 & 0.26 & 1.92 & 0.87 & 0.23 \\
\hline
\end{tabular}

Table 1: Chemical composition of F1272 steel, in weight\%.

\begin{tabular}{|c|c|c|c|c|c|}
\hline $\mathrm{E}(\mathrm{GPa})$ & $\sigma_{\mathrm{y}}(\mathrm{MPa})$ & $\sigma_{\mathrm{u}}(\mathrm{MPa})$ & $\mathrm{e}(\%)$ & $\mathrm{RA}(\%)$ & $\mathrm{k}(\mathrm{MPa})$ \\
\hline 200 & 1596 & 2000 & 11 & 50 & 0.24 \\
\hline
\end{tabular}

Table 2: Tensile properties of $F 1272$ steel $\left(Q+T 200^{\circ} \mathrm{C}\right)$.

\begin{tabular}{|l|c|c|c|}
\hline & CW0.3 & CW0.5 & CW0.7 \\
\hline Shot type & Steel & Steel & Steel \\
\hline Granulometry $(\mathrm{mm})$ & 0.3 & 0.5 & 0.7 \\
\hline Hardness $(\mathrm{HV})$ & $670-730$ & $670-730$ & $670-730$ \\
\hline Density $\left(\mathrm{g} / \mathrm{cm}^{3}\right)$ & 7.8 & 7.8 & 7.8 \\
\hline Air pressure $($ bar) & 2 & 3 & 3 \\
\hline Almen intensity & $8 \mathrm{~A}$ & $14 \mathrm{~A}$ & 1000 \\
\hline Coverage & $100 \%$ & $100 \%$ & 10 \\
\hline
\end{tabular}

Table 3: Shot characteristics and peening conditions. 
Citation: Segurado E, Belzunce FJ, Fernández Pariente I (2017) Fatigue Resistance Study of Quenched and Tempered High-Strength Steel Submitted to Low Intensity Shot Peening Treatments with Different Types of Shots. J Material Sci Eng 6: 401. doi: 10.4172/2169-0022.1000401

Page 3 of 7

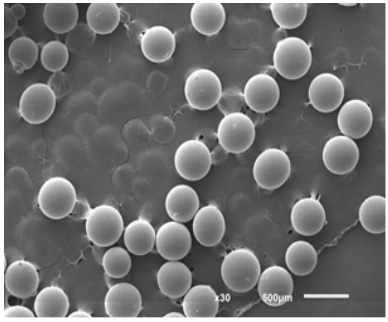

a)

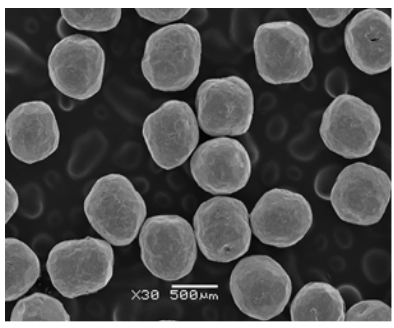

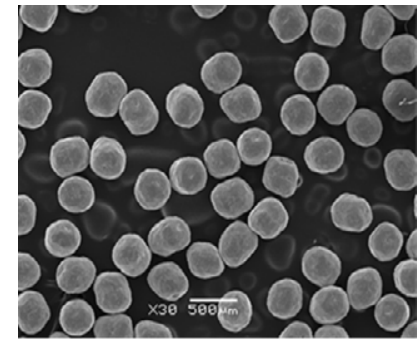

b)

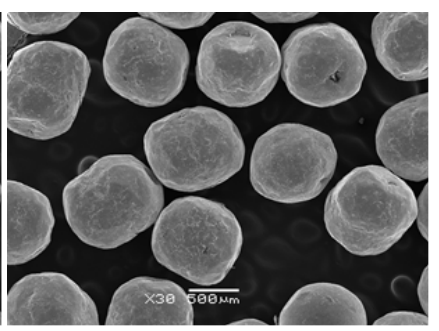

d)
Figure 1: Shot morphologies at 30x, a) ceramic, ZSO.3, b) steel, CW0.3, c) steel, CW0.5, d) steel, CW0.7.

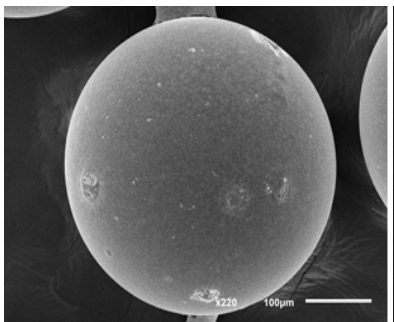

a)

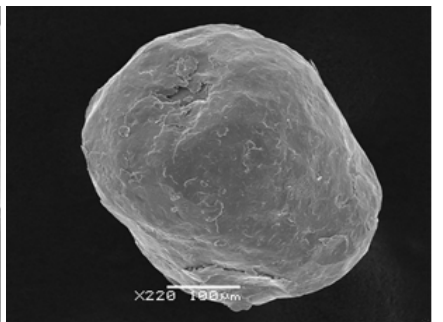

b)
Figure 2: $0.3 \mathrm{~mm}$ diameter shots, a) ZSO.3 b) CW0.3

layers of material were progressively removed step-by-step by electropolishing using a mixture of $94 \%$ acetic acid and $6 \%$ perchloric acid as electrolyte under a voltage of $40-50 \mathrm{~V}$. The slight stress relaxation produced by electro-polishing was also taken into account and corrected in accordance with Sikarskie [16], who has developed a method based on the Moore and Evans procedure [17]. Diffraction data were determined in three different directions $\left(-45,0\right.$ and $\left.+45^{\circ}\right)$ on the sample surface. However, as shot peening stresses are uniform in this plane, average results will be shown. Measurements were made on an X-Stress 3000 G3R device manufactured by Stresstech using the Ka chromium wavelength $(\lambda=0.2291 \mathrm{~nm}),(211)$ diffraction planes, which give a diffraction angle around $156^{\circ}$, and an elastic constant, $\mathrm{E} /(1+v)$, of $168.9 \mathrm{GPa}$ [18].

The procedure for determining the residual stress began with a surface measurement followed by removal of a layer of around $20 \mu \mathrm{m}$. This process was repeated as many times as necessary until reaching a depth at which a residual tensile stress was obtained. The residual stress was always measured on the centre of the specimen, which was previously marked with a permanent marker.

\section{Rotating fatigue tests}

Finally, fatigue tests were carried out on a four-point loading R. R. Moore rotating beam fatigue testing system (fully reversed loading,
$\mathrm{R}=-1$ ) at room temperature under a nominal frequency of $95 \mathrm{~Hz}$ $(5700 \mathrm{rpm})$. The geometry and dimensions of the fatigue specimens are shown in Figure 3. The maximum applied alternative surface stress was $1100 \mathrm{MPa}$ (55\% of the tensile strength of the steel). This load was chosen after performing different tests varying this parameter so that it was always above the steel fatigue limit and, in the case of the best treatments, not far from it. The number of specimens tested under each condition varied between 4 and 6 . Fatigue results are expressed as an average of all the tested samples, although individual values are also reported. Once the specimens had failed, fractographic analyses were carried out under a SEM microscope to detect the origin of the fatigue crack and the fracture pattern.

\section{Results and Discussion}

\section{Roughness}

Table 4 shows the values of the roughness parameters, $\mathrm{Ra}$ and $\mathrm{R}_{\max }$ measured directly on the fatigue samples after the different surface treatments.

As could be expected, a significant increase in roughness was detected by increasing the Almen intensity of the treatments when using the cut wire steel shots. However, a significant difference between the roughness generated by the steel and the ceramic beads was observed for the same intensity and coverage (8A, 100\%): shot peening with the ceramic beads (ZS) produced much lower values of average and maximum roughness. These results are undoubtedly explained by the greater geometric perfection and homogeneity of the zirconia shots (Figures 1 and 2). On the other hand, the increase in the degree of coverage from 100 to $200 \%$ using the same ceramic shots resulted in an increase in the roughness parameters. However, it was verified in a previous study [19] that roughness is not the best parameter for verifying the existence of surface defects, such as folds and small cracks, typical in shot peening treatments. For this reason the surface topography of the specimens was also explored under the

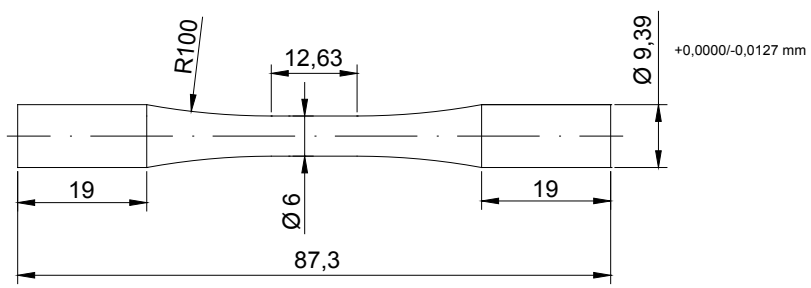

Figure 3: Fatigue sample geometry and dimensions.

\begin{tabular}{|l|l|l|}
\hline Treatments & $\mathbf{R}_{\mathbf{a}}(\boldsymbol{\mu} \mathbf{m})$ & $\mathbf{R}_{\max }(\boldsymbol{\mu} \mathbf{m})$ \\
\hline SP8A-CW $(100 \%)$ & $2.1 \pm 0.1$ & $15.9 \pm 2.1$ \\
\hline SP14A-CW (100\%) & $2.5 \pm 1.1$ & $17.4 \pm 2.1$ \\
\hline SP19A-CW (100\%) & $2.8 \pm 1.2$ & $19.5 \pm 2.2$ \\
\hline SP8A-ZS (100\%) & $1.4 \pm 0.1$ & $11.0 \pm 2.7$ \\
\hline SP8A-ZS (200\%) & $1.8 \pm 0.1$ & $13.3 \pm 2.1$ \\
\hline
\end{tabular}

Table 4: Roughness parameters after the applied mechanical surface treatments.

\begin{tabular}{|l|c|}
\hline Treatment & $\mathbf{Z}_{\mathbf{0}}(\boldsymbol{\mu m})$ \\
\hline SP19A-CW $(100 \%)$ & 375 \\
\hline SP14A-CW $(100 \%)$ & 250 \\
\hline SP8A-CW (100\%) & 150 \\
\hline SP8A-ZS (100\%) & 165 \\
\hline SP8A-ZS (200\%) & 175 \\
\hline
\end{tabular}

Table 5: Depth submitted to compressive residual stresses. 
Citation: Segurado E, Belzunce FJ, Fernández Pariente I (2017) Fatigue Resistance Study of Quenched and Tempered High-Strength Steel Submitted to Low Intensity Shot Peening Treatments with Different Types of Shots. J Material Sci Eng 6: 401. doi: 10.4172/2169-0022.1000401

Page 4 of 7

scanning electron microscope, with representative results being shown in Figure 4.

Under the magnifications shown in Figure 4, differences among treatments are not relevant. However, under a greater magnification (Figure 5), surface defects induced by the mechanical treatments are clearly identified. The sample surface treated with the applied low intensity treatment using ceramic beads (SP8A-ZS) under coverages of $100 \%$ hardly produced any significant defect, while sample surfaces treated with the steel balls always showed small cracks and sharp notches due to shot impacts at high velocity. These results can be justified based on the shape of the shots, previously shown in Figures 1 and 2 (in this respect, the perfect spherical shape of the zirconia shots is once again worth highlighting). On the other hand, the applied treatment using

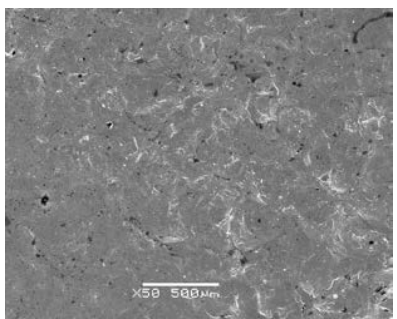

a)

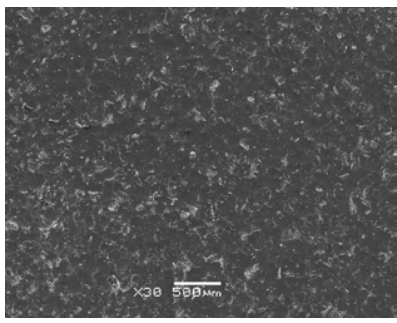

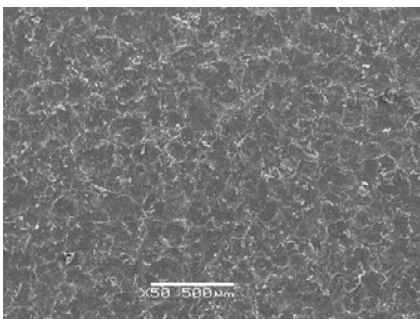

b)

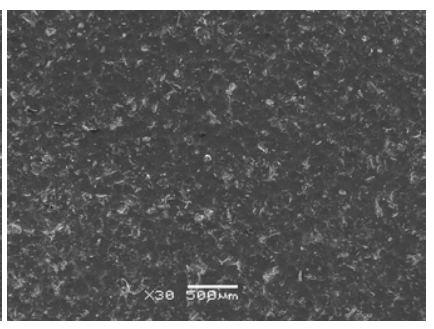

Figure 4: Surface topography after different surface treatments. a) SP19A-CW $(100 \%) 50 x, b)$ SP8A-CW (100\%) 50x, c)SP8A-ZS (100\%) 30x d) SP8A-ZS $(200 \%) 30 x$.

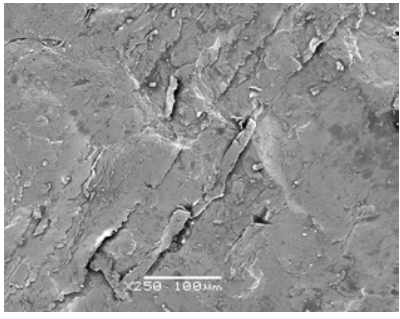

a) $\mathrm{SP} 19 \mathrm{~A}-\mathrm{CW}(100 \%)$

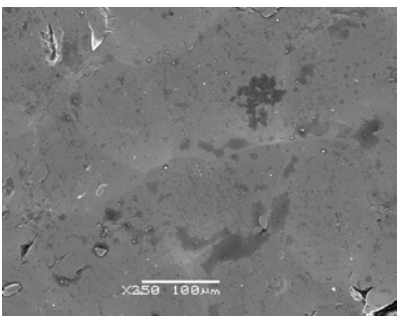

a) $\operatorname{SP} 8 \mathrm{~A}-\mathrm{ZS}(100 \%)$

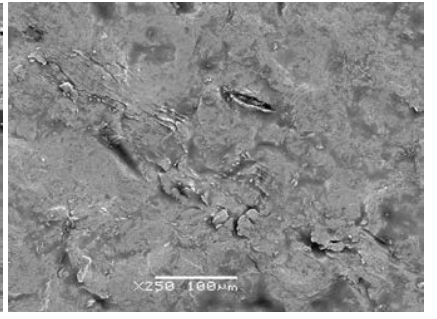

b) SP $8 \mathrm{~A}-\mathrm{CW}(100 \%)$

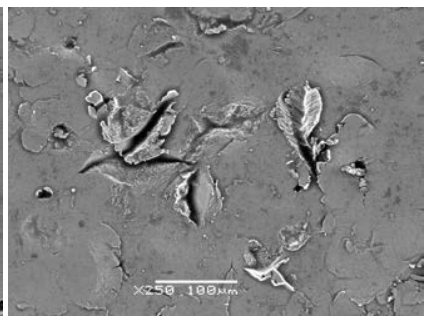

d) SP8A-ZS (200\%)
Figure 5: Surface topography after different surface mechanical treatments. 250x. ceramic beads under coverages of $200 \%$ finally gave rise to quite similar defects to those produced when using steel balls.

\section{Residual stress profiles}

Figure 6 shows the residual stress profiles generated after applying the studied surface treatments. The shapes of the profiles corresponding to the same intensity $(8 \mathrm{~A})$ are quite similar, revealing a surface compressive residual stress with a magnitude of between 1000 and $1050 \mathrm{MPa}$ and a maximum compressive residual stress of around $1200 \mathrm{MPa}$ located at a depth of $60-70 \mu \mathrm{m}$ followed by a progressive increase in stress until reaching small positive values, thus defining the depth affected by the residual compressive stress field. Only a small increase in the depth submitted to compressive residual stresses was observed when zirconia beads were used instead of steel shots (8A) and also when coverage was increased to $200 \%$ using the ceramic beads. The small profile change due to the use of the ceramic beads is justified by their greater hardness (Table 3) [3].

The residual stress profiles measured in the case of the highest intensity treatments (obtained using steel balls) were nearly similar at low depths $(<70-80 \mu \mathrm{m})$, the greatest difference being the depth submitted to compressive residual stresses (denominated $\mathrm{Z}_{0}$ ), which increases as the intensity of the treatment increases. The $Z_{0}$ values measured in all the mechanical treatments are shown in Table 5.

The profile of the full width at half maximum parameter (FWHM) can be seen in Figure 7. The evolution of this parameter in this high strength steel is worth highlighting. There is a clear increase in this parameter (hardening) near the surface of the samples, although this reaches a minimum at a depth of between 80 and $100 \mu \mathrm{m}$ from the surface and then increases until reaching the level corresponding to the base steel $\left(5.8^{\circ}\right)$. The observed decrease in the FWHM parameter in this steel at the aforementioned depth, also observed in other high strength steels [9], is probably the result of dislocation re-arrangement. Due to quenching followed by a low temperature tempering, the base steel has a high distorted structure with a high hardness and peeninginduced plastic deformation resulted in a lower-energy dislocation arrangement. This consequently gave rise to a reduction in the FWHM parameter in the sub-surface regions, although an increase in FWHM was observed in the first $80-100 \mu \mathrm{m}$.

Surface hardening produced by shot peening treatments is best represented as the difference between the superficial FWHM and the minimum FWHM (stabilized microstructure due to shot peening), values which are shown in Table 6. This index is a clear indication of the effect produced in the sample surface by the plastic deformation produced by the repeated shot impacts. Ceramic beads induce a higher hardening effect due their much higher hardness compared with steel shots (Table 3), this effect also being much more notable in the case of the $200 \%$ coverage treatment. It should likewise be recalled here that the excessive surface plasticity and hardening induced in the latter case also produced significant surface defects (Figure 5d).

\section{Fatigue lives}

Figure 8 shows the individual and the average fatigue life results obtained after the application of the studied mechanical treatments. The fatigue results obtained for the untreated specimens (NSP) are also shown for the sake of comparison. It should first be noted that all the applied surface treatments improved the fatigue behaviour of the untreated specimens at least 4 -fold.

Shot peening with zirconia beads under an intensity of $8 \mathrm{~A}$ and 
Citation: Segurado E, Belzunce FJ, Fernández Pariente I (2017) Fatigue Resistance Study of Quenched and Tempered High-Strength Steel Submitted to Low Intensity Shot Peening Treatments with Different Types of Shots. J Material Sci Eng 6: 401. doi: 10.4172/2169-0022.1000401

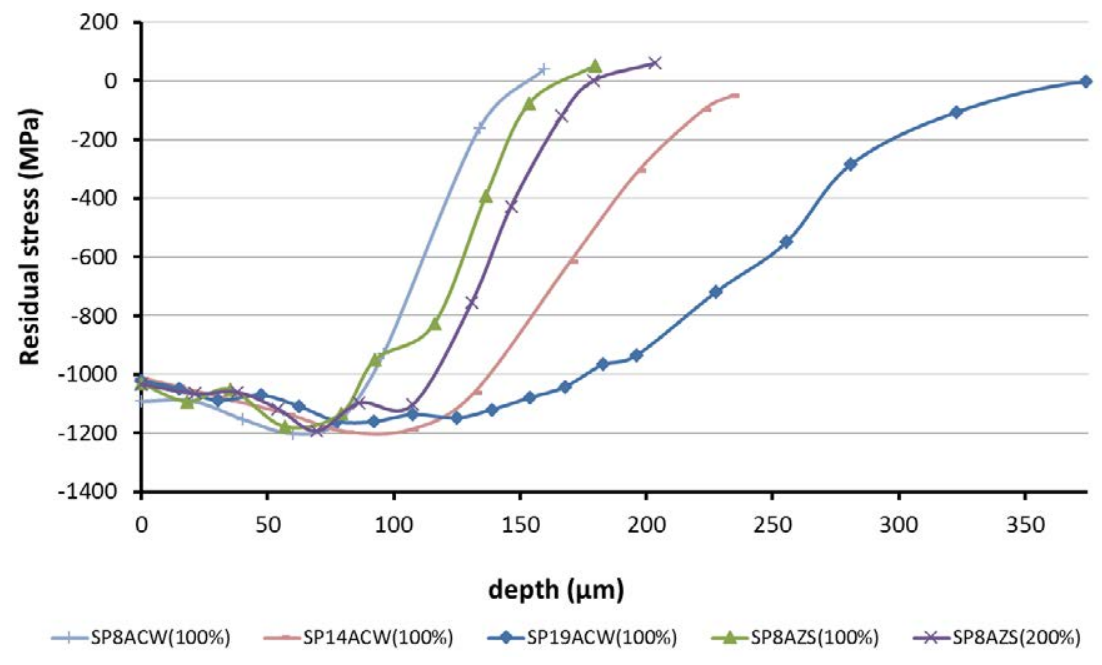

Figure 6: Residual stress profiles corresponding to the different surface treatments.

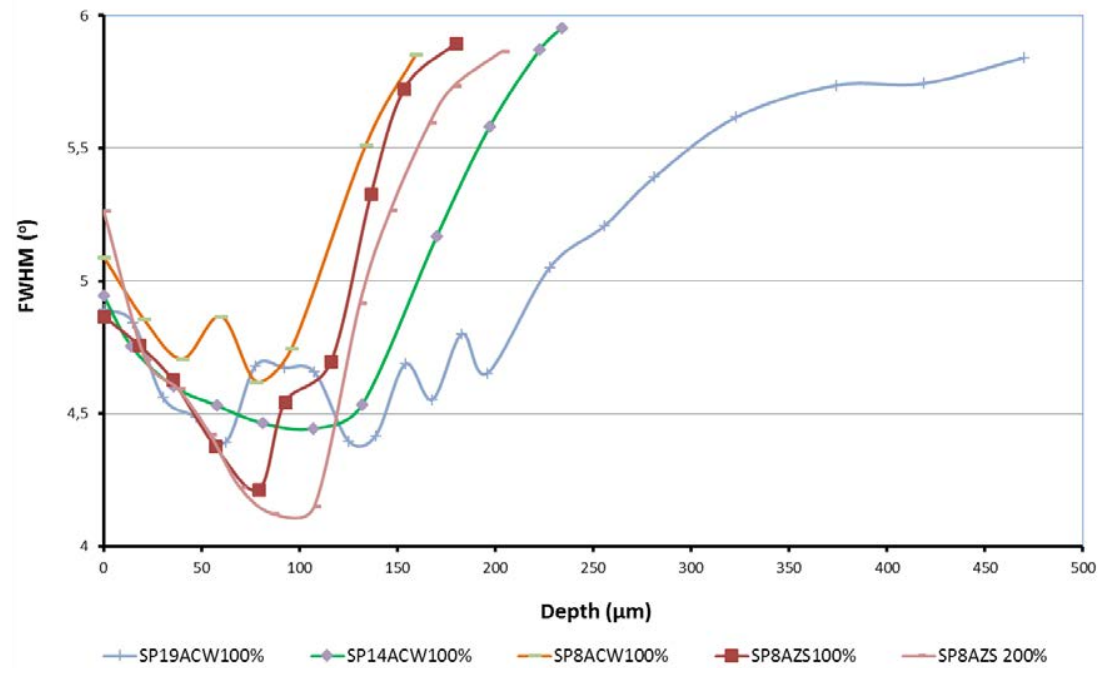

Figure 7: FWHM profiles measured in the different surface treatments.

\begin{tabular}{|l|c|c|c|}
\hline Treatment & FWHM $_{\text {sup }}$ & FWHM $_{\text {min }}$ & Surface hardening index $^{{ }^{\circ}}$ ) \\
\hline SP19A-CW (100\%) & 4.89 & 4.39 & 0.5 \\
\hline SP14A-CW (100\%) & 4.94 & 4.44 & 0.5 \\
\hline SP8A-CW (100\%) & 5.09 & 4.62 & 0.47 \\
\hline SP8A-ZS (100\%) & 4.86 & 4.21 & 0.65 \\
\hline SP8A-ZS (200\%) & 5.26 & 4.12 & 1.14 \\
\hline
\end{tabular}

Table 6: Surface hardening $\left(\mathrm{FWHM}_{\text {sup }}-\mathrm{FWHM}_{\text {min }}\right)$.

$100 \%$ coverage produced a much longer fatigue life than that obtained with the rest of the evaluated surface treatments. An average fatigue life under this high alternative stress greater than 900,000 cycles was measured, the lowest fatigue lives on individual specimens always being greater than 400,000 cycles, a fatigue life which was never attained in any individual test performed with the other treatments. The main distinctive characteristic of this treatment is the much lower surface damage induced by the impacts with the ceramic shots under $100 \%$ coverage (Figure 5), which in turn was already justified by the perfect spherical shape of these projectiles.
Moreover, Figure 8 also shows the major deterioration in fatigue life produced by prolonging the surface treatment when using zirconia beads. After the $200 \%$ coverage using zirconia beads, fatigue life decreased more than 10 -fold due to the surface damage finally induced after such a prolonged mechanical treatment (Figure 5).

While greatly increasing the depth affected by the residual compression stresses (Table 5), the use of steel shots under higher intensities also induces much greater surface damage, which limits the aforementioned beneficial effect. Both effects, the depth submitted to compressive stresses and the magnitude of surface defects nearly offset one another. Hence, fatigue lives were hardly different when the intensity was varied between $8 \mathrm{~A}$ to $19 \mathrm{~A}$ using steel shots (average fatigue lives of between 40,000 and 60,000 cycles).

It should be recalled here that the fatigue tests were carried out under rotating bending loads, where the alternative applied stress $(1100 \mathrm{MPa})$ reached its maximum value on the surface of the specimen, descending linearly until reaching zero on the specimen's central axis, 
Citation: Segurado E, Belzunce FJ, Fernández Pariente I (2017) Fatigue Resistance Study of Quenched and Tempered High-Strength Steel Submitted to Low Intensity Shot Peening Treatments with Different Types of Shots. J Material Sci Eng 6: 401. doi: 10.4172/2169-0022.1000401

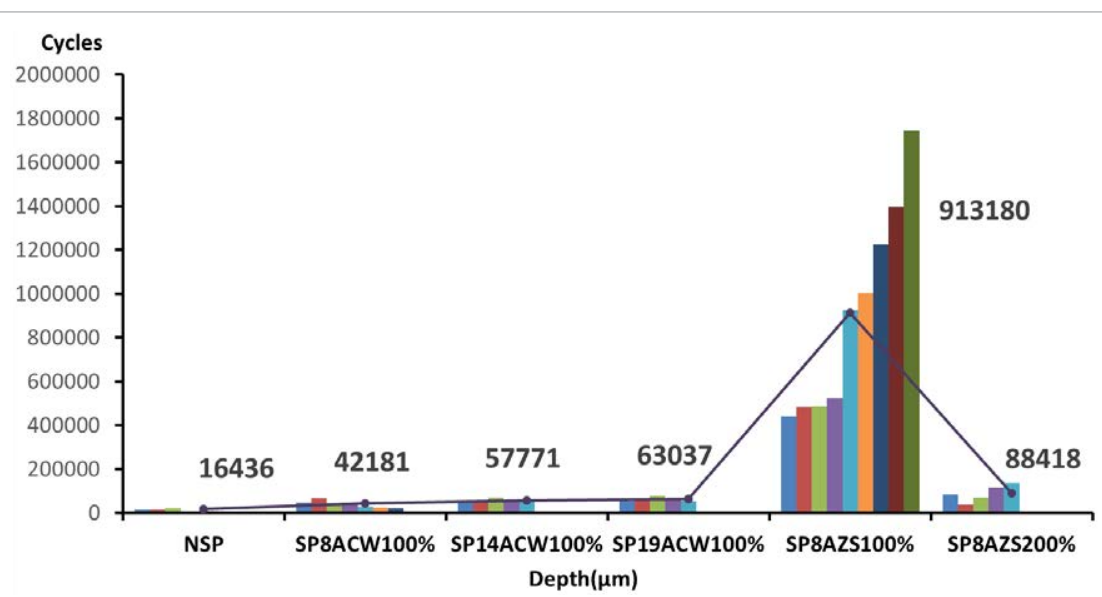

Figure 8: Average fatigue lives and individual results (bars) under rotating bending. Maximum applied stress of $1100 \mathrm{MPa}$
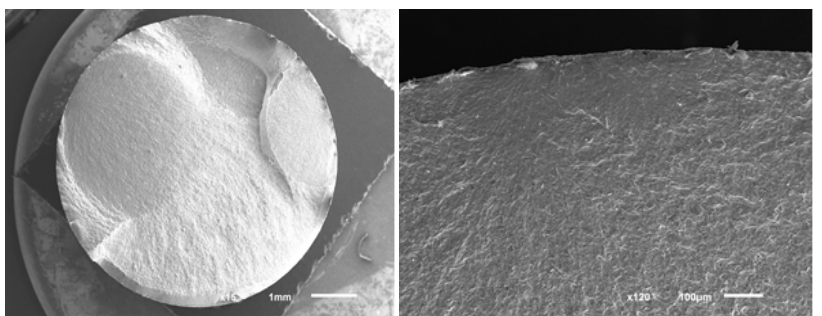

a)
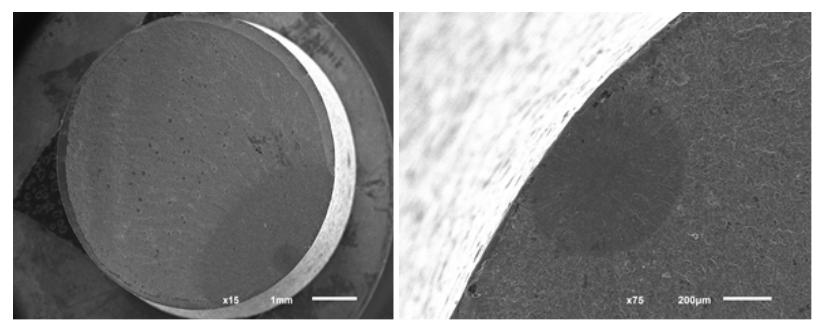

d)

Figure 9: Fatigue failure of fatigue samples submitted to different mechanical treatments: a) SP8A-CW (100\%) 15x, b) SP8A-CW (100\%) 120x, c) SP8A-ZS $(100 \%) 15 x$ y d) SP8A-ZS $(100 \%) 75 x$.

located at a depth of $3 \mathrm{~mm}$ (specimens with a diameter of $6 \mathrm{~mm}$ ). Under these conditions, fatigue cracks are expected to initiate on the surface of the specimen. Surface fatigue initiation took place in all the treatments using cut wire steel shots and also in those using ceramic beads under $200 \%$ coverage due to the previously mentioned surface defects. However, all the specimens treated with zirconia shots and $100 \%$ coverage failed due to fatigue cracks internally initiated at hard inclusions located at depths greater than $165 \mu \mathrm{m}$ (value of $Z_{0}$ in Table 5 ). That is, fatigue crack initiation always took place in these tests in the region not affected by the residual compressive stresses induced by the mechanical treatment.

Representative examples of the fatigue failures observed in these tests are shown in Figure 9.

Figure $9 \mathrm{a}$ and $9 \mathrm{~b}$ show a typical example of surface fatigue crack initiation in a surface defect produced by the high velocity impact of the cut wire steel shots, while the internal fatigue crack initiation in one of the specimens submitted to $8 \mathrm{~A}$ intensity using zirconia beads and $100 \%$ coverage is presented in Figure $9 \mathrm{c}$ and $9 \mathrm{~d}$. A magnified image

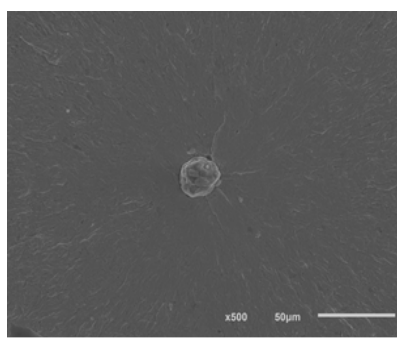

a)

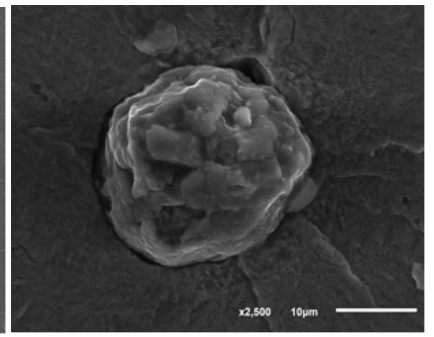

b)
Figure 10: Fatigue crack initiation region after SP8A-ZS (100\%) treatment. Alumina inclusion. a) $500 x y$ b) $2500 x$

of the fatigue crack initiation zone can be seen in Figure 10. Internal crack initiation always took place around hard non-metallic inclusions, which were analysed under the scanning electron microscope, being in all cases mixed oxides of aluminium, magnesium and/or calcium.

A fatigue crack initiates internally when the stress concentration factor due to surface defects generated by shot peening is minimized. This is because the compressive residual stress belt induced in this case is able to avoid crack initiation on the surface region, consequently triggering an internal fatigue crack initiation process. In these cases, the stress intensity factor acting on the largest surface defect, provided by the effective stress $\left(\sigma_{e}\right)$, which is in turn the sum of the applied $\left(\sigma_{\mathrm{a}}\right)$ and the residual $\left(\sigma_{\mathrm{r}}\right)$ stresses, was lower than the stress intensity factor acting on the largest inclusion present in the sub-surface region, which is submitted to a lower bending stress. However, the compressive residual stress also decreased at this location to a non-significant value (Figure 11).

Following this analysis, it may hence be stated that the so-called internal fatigue damage mechanism is non-dependent on surface characteristics, depending only on the microstructure of the steel, specifically on the existence of microstructural stress concentrators such as alumina or other types of hard non-metallic inclusions.

It is also worth highlighting that the dispersion of the SP8A-ZS (100\%) fatigue results observed in Figure 6 is not due to the applied surface treatment, but to the statistical distribution of the hard and rigid inclusions present in this steel. Under this consideration, the best way to improve the fatigue strength of the steel, once the surface has been protected by means of an appropriate mechanical treatment, would be 


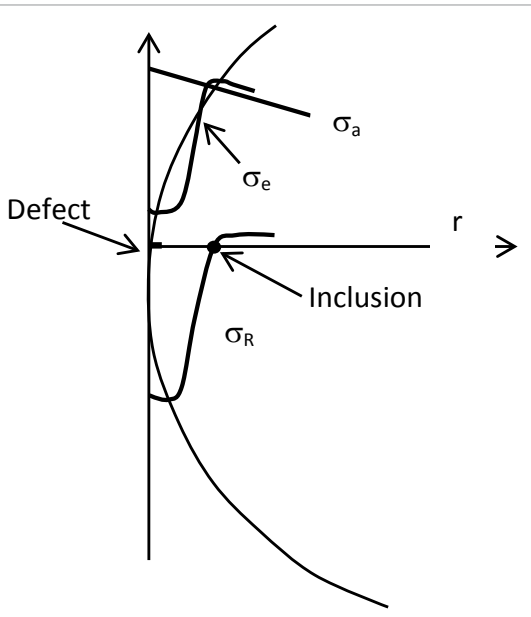

Figure 11: Stresses acting under bending on shot peened fatigue specimens Fatigue crack initiation at a subsurface inclusion where the effective stress, $\sigma_{\varepsilon}\left(\sigma_{\varepsilon}=\sigma_{\alpha}+\sigma_{\mathrm{p}}\right)$, reaches the maximum $\mathrm{v}$.

to use special processing techniques to obtain a cleaner product with lower inclusion densities and inclusions of smaller sizes.

\section{Conclusions}

Hardly any significant defect was produced on surfaces treated with low intensity treatment using zirconia beads (SP8A-ZS) under $100 \%$ coverages, while sample surfaces treated with steel balls under the same intensity always showed small cracks and sharp notches caused by high velocity shot impacts. These results were justified by the perfect spherical shape of the zirconia shots.

The residual stress profiles produced after the application of the different surface treatments using different types of shots, intensities and coverages were very similar for depths lower than 70-80 $\mu \mathrm{m}$, the main difference being the depth affected by the presence of compressive residual stresses, which slightly increases when using zirconia beads and with increasing coverage, the increase of this parameter being much more significant when the intensity of the treatment increases.

Shot peening with zirconia beads under an intensity of $8 \mathrm{~A}$ and $100 \%$ coverage gave rise to a much longer fatigue life than that obtained with the rest of the evaluated surface treatments. The main distinctive characteristic of this treatment is the much lower surface damage induced by the impacts with the ceramic shots under $100 \%$ coverage, which was in turn already justified by the perfect spherical shape of these projectiles. Moreover, a major deterioration in the fatigue life was produced by prolonging the surface treatment with the zirconia beads. After a $200 \%$ coverage treatment, fatigue life decreased more than 10 -fold due to the surface damage finally induced as a consequence of excessive plastic surface deformation following such a prolonged mechanical treatment.

Furthermore, the treatment with zirconia shots under an intensity of $8 \mathrm{~A}$ and $100 \%$ coverage always gave rise to internal initiation of the fatigue crack at a depth where the residual compression stresses induced in the treatment disappeared and due to the stress concentration associated with the presence of hard and rigid nonmetallic inclusions, even though the applied rotational bending fatigue tests always produced the maximum alternative stress on the surface of the test specimen.

\section{References}

1. MIC, Shot Peening Applications, (8thedn), Metal Improvement Company, USA 2001

2. Abadie FX (2009) Shot peening: a dynamic application and its future. MFN Publishing House.

3. Kritzler J, Wubbenhorst W (2002) Inducing compressive stresses through controlled shot peening. ASM International, Member/Customer Service Center, Materials Park, $\mathrm{OH}$ 44073-0002, USA, pp: 345-358.

4. Tekeli S (2002) Enhancement of fatigue strength of SAE 9245 steel by shot peening. Materials letters 57: 604-608.

5. Aggarwal ML, Khan RA, Agrawal VP (2005) Influence of shot peening intensity on fatigue design reliability of $65 \mathrm{Si} 7 \mathrm{Spring}$ Steel.

6. Torres MAS, Voorwald HJC (2002) An evaluation of shot peening, residual stress and stress relaxation on the fatigue life of AISI 4340 steel. Internationa Journal of Fatigue 24: 877-886.

7. Vielma AT, Llaneza V, Belzunce FJ (2014) Effect of coverage and double peening treatments on the fatigue life of a quenched and tempered structura steel. Surface and Coatings Technology 249: 75-83.

8. Llaneza V, Belzunce FJ (2015) Optimal shot peening treatments to maximize the fatigue life of quenched and tempered steels. Journal of Materials Engineering and Performance 24: 2806-2815.

9. Llaneza V, Belzunce FJ (2015) Study of the effects produced by shot peening on the surface of quenched and tempered steels: roughness, residual stresse and work hardening. Applied Surface Science 356: 475-485.

10. Fu P, Zhan K, Jiang C (2013) Micro-structure and surface layer properties of 18CrNiMo7-6 steel after multistep shot peening. Materials \& Design 51: 309314.

11. Abadie F (2010) Enhancement of Shot Peening performance on high strength steel parts. Metal Finishing News 11: 16-18.

12. Strip T (2008) Holder and Gage for Shot Peening. SAE Standard J 442.

13. Standard SAE (2003) J443-Procedures for using standard shot peening test strip. SAE International.

14. Noyan IC, Cohen JB (2013) Residual stress: measurement by diffraction and interpretation. Springer.

15. Prevey PS (1986) X-ray diffraction residual stress techniques. ASM International, ASM Handbook 10: 380-392.

16. Sikarskie DL (1967) A Series form of Correction to Stresses Measured using X-Ray Diffraction. Aime Met Soc Trans 239: 577-580.

17. Moore MG, Evans WP (1958) Mathematical correction for stress in removed layers in X-ray diffraction residual stress analysis (No. 580035). SAE Technical Paper.

18. Fitzpatrick ME, Fry AT, Holdway P, Kandil FA, Shackleton J, et al. (2005) Determination of residual stresses by $\mathrm{X}$-ray diffraction.

19. Segurado E, Belzunce FJ (2016) The use of double surface treatments to increase the fatigue life of a quenched and tempered high-strength steel. Surface Modification Technologies XXIX, Edit. T.S. Sudarshan and N.A.J. Sommers pp: $38-46$ 